Norfolk. Trained in the Royal Dockyards as a shipwright, he became surveyor of the Navy and designed many fine ships. $\mathrm{He}$ is the only naval architect to whom the Royal Society has given its highest award, the Copley Medal. After retirement, he lived at Taunton, where there is a memorial to him in St. Mary's Church, a part of the inseription being an extract from a report by a House of Commons committee.

Though the great county of Lincolnshire, second only in size to Yorkshire, has endless attractions, and though it contains the birthplaces of John Wesley, Tennyson, Sir John Franklin, George Bass, Franklin's cousin Matthew Flinders, and also of Dr. Robert Smith (1689-1768), the Plumian professor who founded the Smith Prizes at Cambridge and gave to Trinity College Roubillac's statue of Newton, for the lover of science no buildings can rival in interest the small manor house at Woolsthorpe, seven miles south of Grantham, in which Newton was born; Colsterworth Church, in the baptismal register of which is the entry : "Isaac son of Isaac and Hanna Newton, Jany. 1, 1643"; and Bishop Fox's Free Grammar School at Grantham, where Newton was taught by Henry Stokes. In 1858 Lord Brougham unveiled Grantham's fine bronze statue of Newton, and in 1927 the town was the scene of meetings commemorating the bicentenary of Newton's death, at which Sir J. J. Thomson, Sir Frank Dyson, Sir James Jeans and Sir Horace Lamb paid tribute to Newton's genius. Later on, in 1942, on a limited scale, and in 1946, on an international scale, the Royal Society commemorated in a worthy manner the tercentenary of Newton's birth, one outcome of which was that the Woolsthorpe manor house passed into the keeping of the National Trust and is thus preserved to the nation. The house is still inhabited, but the principal rooms are open to the public at certain times. Newton was not only born there, but it was to Woolsthorpe he returned in 1665 when the University of Cambridge was closed on account of the plague, and he remained there until 1667. "By the time of his return to Cambridge," said Prof. E. N. da C. Andrade in 1946, "it is tolerably certain that he had already firmly laid the foundations of his work in the three great fields with which his name is for ever associated-the calculus, the nature of white light and universal gravitation and its consequences. ..."

With Cambridge and Cambridgeshire it is not proposed to deal, for excellent guide-books and histories are easily obtainable, giving particulars of the colleges and institutions and the many men of science who have added lustre to the University, and whom the University has honoured.

\section{EVOLUTIONARY TRENDS AND CLASSIFICATION}

A SYMPOSIUM with the general title of "Fvolutionary Trends and Classification" was held by the Systematics Association in the Leeds City Museum on April 28. This meeting was of particular significance in that it represented the first implementation of a decision made by the Council of the Association to extend the activities of the Association to provincial centres. The organization was in the hands of a 'Northern Committee', but the meeting was in no sense a local one, for among the eighty zoologists, botanists and palæontologists attending were representatives of various institutions and societies from London to Edinburgh. The two sessions were under the chairmanship of, respectively, Captain C. Diver, director-general of the Nature Conservancy, and Prof. Irene Manton, professor of botany in the University of Leeds.

The first paper was given by Dr. O. W. Richards (Imperial College of Science and Technology, London), who posed the question "Is Phylogenetic Speculation Necessary to the Practising Taxonomist?" He pointed out that the work of the taxonomist is fourfold: the determination of specimens for other workers, the description of new species, the improvement of the arrangement of species and, lastly, the attempt to fit the facts into a phylogenetic scheme. The first three can be carried out without relation to the fourth, but the best classification (permitting successful predictions) will necessarily illuminate phylogeny, and, at the same time, some phylogenetic theory is always valuable as a working tool. For example, even convergence, if not too strictly conditioned by very specialized adaptation, may be an indication of a remote relationship in that the forms belong to one stock which still retains certain potentialities. 'Outside' evidence, such as data from geographical distribution, etc., is usually admitted in classification, and this automatically introduces the idea of phylogeny. Were this not the case, there is no reason why a genus should not consist of odd species dotted over the continents of the world, or why most wingless Diptera should not be considered to be allied. Nevertheless, it needs to be emphasized that many more facts are necessary to establish a probable phylogeny than may be necessary for mere identifications. For judging the correctness of phylogenies based on recent material, insects are very suitable. Five sources of 'outside' evidence which may be tapped are the rather scanty fossil record, the geographical picture, the cytological evidence (chiefly concerned with sex-chromosome mechanisms) and the foods of phytophagous species. The close correlation between this evidence and the morphological classification could only represent an incredible series of coincidences were this classification not a good index to phylogeny.

A strikingly different aspect of biology was dealt with by Prof. J. Small (Queen's University, Belfast), who dealt with "Trends in the Degree of Diversification in Diatoms". The Tertiary fossil history of this group of plants is known in considerable detail and shows great regularity. Drawing a sharp distinction between short-lived species ('Evanescent' or ' $E$ ') and long-lived ('Permanent' or 'P'), he showed that the latter appear to become unstable in their reproductive mechanisms at more or less regular intervals (of the order of seven million years), under. going specific mutation to give rise to new species. Similarly, the oldest species will have produced the greatest number of varieties, etc. Generic origins and extinctions have maintained a balance with specific origins and extinctions so that the proportions of generic aizes have remained more or less constant. Merely recent or merely fossil genera rarely contain more than eight species. These findings are held to support the abrupt methods of speciation claimed by Willis and by Goldschmidt. It was suggested in discussion that there is much in this topic which might be discussed at a separate meeting. 
Dr. A. J. Cain (University of Oxford) closed the morning session with a paper on "Local Evolution and Taxonomy in very Polymorphic Species", in which he showed, from his examples, that such polymorphy is highly dependent upon natural selection. His general conclusion was that 'microevolution' differs in no essential respect from the 'macro-evolution' illustrated by the large-scale trends seen by palæontologists. This was demonstrated, first, by reference to gastropods (particularly the genus Cepcea). Here, the variation of colour and banding patterns appears to be closely related to the background pattern, and this has been confirmed by marking experiments. The polymorphism of some birds, particularly the lorikeets, was also used to demonstrate that present-day geographic variation reveals evolution in progress. The taxonomist, faced with the necessity for describing such variation adequately, may be forced to abandon the typological method and adopt a notation expressing trends and not demonstrating conformity to a static description.

Mr. E. Milne-Redhead emphasized that such a notation is sometimes needed in botany too. Captain Diver and Dr. J. Crosby took part in the discussion, which was chiefly concerned with the significance of the variation between snail populations, and Dr. Cain replied.

In the afternoon, Dr. R. M. C. Eagar (University of Manchester) deait with "Some Problems of Invertebrate Palæontology". In addition to difficulties provided by the nature and supply of fossil material, where the picture is clear enough, variation and change may be followed both vertically and horizontally. Thus, species in palæontology are, theoretically, arbitrary units. Where species are very variable and can be traced upwards through strata as a succession of apparently interbreeding communities, cross-sections of which have stratigraphical utility, classical taxonomy needs modification or replacement by a special utilitarian system. In the Anthracosiidæ, a binomial system of morphological species within natural groups has worked well for the stratigrapher and has been successfully applied to the description of small continuous changes. The establishment of the 'natural groups' is of great importance, and ultimately it may be possible to institute a trinomial nomenclature satisfying both stratigrapher and systematist. Nevertheless, there will long remain groups needing individual syatems of terminology.

In the second afternoon paper, Dr. G. Heslop Harrison (King's College, Newcastle) spoke on "The Probable Origin, Phylogeny and Evolution of the Class Insectr, with Special Reference to the Classification of the Hemiptera-Homoptera". A new interpretation was given of the subjects indicated in the title. Examination of the evidence purporting to indicate 'explosive evolution' in the origin of the Insecta shows it to be unreliable, it being likely that much fossil evidenee which might have stretched back to the Silurian has been removed by the very extensive Permo-Carboniferous glaciations. The probable times of origin and courses of events in the histories of various orders were reviewed, with particular attention paid to the Hemiptera. The shortcomings of the existing systems of classification in the Hemiptera-Homoptera were pointed out, and new alternatives based on phylogeny and evolutionary concepts were proposed. In the discussion which followed, P. C. Sylvester-Bradley claimed particularly that the evidence in favour of 'explosive evolution' is by no means refuted, particularly in the development of wings.

Prof. P. W. Richards (University College of North Wales, Bangor) then presented $a$ paper entitled "Evolutionary Trends and Classification in the Bryophyta". He pointed out that the poor fossil record of the mosses and liverworts gives no solid basis for phylogenetic speculation. Various extensive morphological series established within the group (particularly by the work of Goebel) give strong evidence of evolutionary trends, usually from complex to relatively simple. Such a trend is well illustrated by the Marchantia-Riccia series in the Marchantiales. Here, the genus Dumortiera is generally similar in complexity to Marchantia, but the mature thallus lacks the system of air-chambers and pores. $D$. nepalensis, however, shows in the younger parts of the thallus partitions between air-ehambers which break down without becoming functional. This trend of simplification has recently been confirmed by the genetic studies of Burgeff, who maintained cultures of Marchantia in which a remarkable range of morphological types arose as mutations, either spontaneously or following crossing. Many of the mutants and mutant-combinations resemble other, simpler, members of the Marchantiales.

Such a trend to simplification may depend upon the pressure of competition, which has restricted many species to temporary habitats with a consequent telescoping of the life-cycle. A classification which takes this into account will list complex species first; only Evan's classification of the liverworts has consistently followed this plan. In the subsequent discussion, Prof. A. R. Gemmell directed attention to the frequent association of bryophytes with fungi and inquired if this might be associated with the simplifying trend.

The last paper, given by Dr. J. M. Thoday (University of Sheffield), was a theoretical comparison of "The Units of Evolution and the Units of Classifieation". It was pointed out that systematists seeking explicitly for a natural unit of classification with a genetical basis attempt with some success to draw boundaries across which gene-exchange is so limited that the groups thus separated may be regarded as distinct units of evolution. However, the sizo and complexity of units of evolution vary according to the broeding system. Among vegetatively reproduced forms, obligate apomicts and obligatorily self-fertilized forms, the contemporary unit of evolution is the individual, while among out-breeders it is the population within which gene exchange occurs (and this may cover more than one species). Furthermore, breeding systems and structures may change and, with them, the size and complexity of the unit of evolution. Self-fortilized forms may become out-breeders or vice versa. Geographical or ecological barriers may break down so that two units may fuse, even if their species retain their essential identities. For these reasons, units of evolution cannot be, at the same time, satisfactory units of classification. If 'species' should become a word meaning 'unit of evolution', a new word will be required for the basic unit of systematics.

The longest discussion of the day followed this paper. Mr. P. C. Sylvester-Bradley directed attention to the usefulness of Gilmour and Gregor's 'deme' terminology. Dr. J. Crosby mentioned the greater ease with which out-breeding can give way to inbreeding rather than the reverse, and Dr. H. G. 
Baker concurred. Prof. Manton pointed out that apomixis (loosely defined) is not an exclusively recent development, and pointed to those ferns which fall into neat species despite apogamy. Dr. Baker emphasized that the worst classificatory tangles involve facultative apomicts. Dr. Heslop Harrison pointed to similar occurrences in the insect world. Drs. Cain and Richards also spoke on the nature of classificatory units, and Dr. Thoday replied to all the points. Dr. Crosby suggested that the significance of the species should not be denied because there are groups in which other concepts are necessary. Thus, the meeting ended with a very hopeful augury of future discussion. H. G. BAKER

\section{OBITUARIES}

\section{Prof. Aimé Auguste Cotton}

Prof. Armé Cotron, one of the most distinguished Frenchmen of his time and an experimenter of no mean order, died on April 16 at Sèvres. He was born on October 9, 1869, at Bourg-en-Bresse, where his father was a teacher of mathematics. He received his early education at the Lycée de Bourg, where he first became interested in experimental science, and at the Lycée de Clermont-Ferrand, where he received special training in mathematics. $\mathrm{He}$ entered the École Normale Supérieure in 1890, and hence came into contact with such men as Henri Poincaré, Emile Picard and Mareel Brillouin. In 1893 he became agrégé des sciences, and in 1896 obtained his doctorate.

Cotton's career as a scientific worker began at the University of Toulouse, where he was maître de conférences from 1895 until 1901. In 1900, he was given the title of professor in the University of Toulouse, and was also appointed chargé de cours in the École Normale Supérieure, where he was responsible for the training of students up to 1922 ; he was also on the staff of the corresponding girls' school, then at Sèvres, where he was assisted by his wife. While still on the staff of the latter institutions, he was appointed to the chair of theoretical and celestial physics at the Sorbonne in 1920, and to the chair of general physics in 1922. $\mathrm{He}$ was elected a member of the Paris Acaderny of Sciences in November 1923, and was president of the Academy in 1938.

At the outset of his career, Cotton made important discoveries concerning the absorption of circularly polarized light in coloured liquids. $H_{\theta}$ found that when a beam of unpolarized white light, after traversing such a liquid, is submitted to examination by an analyser arranged for the detection of circularly polarized light, two differently coloured beams of different intensities were obtained. This was followed by the discovery of the phenomenon of anomalous rotatory dispersion - that in a coloured liquid which exhibits the property of optical rotation, the amount of rotation of the plane of polarization depends on the wave-length of the light in a manner quite different from that observed with uncoloured liquids. These two discoveries were of considerable importance in settling certain questions of molecular structure.

Following Zeeman's discovery of the effect of a magnetic field on emission spectra, Cotton carried out analogous experiments on absorption spectra, and showed that absorption lines were also changed by the application of a magnetic field to the absorbing medium ; he discovered that the absorption spectrum of a coloured flame showed magnetic double-refraction effects in the neighbourhood of the absorption lines. In order to give greater precision to such measurements, Cotton devised a special form of electromagnetic balance for the measurement of magnetic fields, and he was able to prove that the Zeeman effect is independent of temperature. It is often forgotten that, in collaboration with Pierre Weiss, he determined the specific charge on the electron by measurements on the blue rays of zinc excited in an accurately known magnetic field.

Cotton was also associated with Henri Mouton in a series of important researches on ultramicroscopic particles, designing a special total-reflexion ultramicroscope for the purpose. Together, they examined the magneto-optical properties of colloids and found that these substances exhibited magneto-optical rotation and dispersion, in addition to the magnetic double refraction previously observed by Majorana. From these experiments they concluded that the colloid particles were anisotropic and so oriented themselves under the influence of a magnetic field. In England, the results of their great series of experiments on the magnetic double refraction of homo. geneous organic liquids, analogous to the Kerr effect, are summarized as the Cotton-Mouton Law.

Because of these experiments, Cotton will always be remembered; but perhaps he will be even better remembered in Britain because he was the first to construct in 1928 a large electromagnet for experimental purposes. This magnet is lodged at BelleVue, Paris, and while bigger and possibly more efficient magnets have since been made, one must pay tribute to the great enterprise and vision which inspired its building. It continues to give good service, and during the War its work was supplemented by the building of a very large permanent magnet under the noses of the Germans.

Prof. Cotton was a very charming person, and will certainly be missed by a wide circle of friends. In his younger days he was associated with the defenders of Dreyfus. $\mathrm{H}_{\theta}$ was interested in Esperanto. In the First World War he took an active part in the development of sound-ranging devices. During the recent occupation of France he did not escape German attentions, and for some weeks was kept in Fresnes prison with some of his fellow academicians. He was three times honoured by the Academy of Sciences; he received the Pierson-Perrin Prize in 1907, the Caze Prize in 1918 and the Albert I of Monaco Prize in 1928.

We deeply sympathize with all his friends in their great loss, and in particular with Mme. Cotton, his wife, M. and Mme. Eugène Cotton (son and daughterin-law) and M. and Mme. Manigault (son-in-law and daughter).

L. F. Bates

\section{Mr. W. W. Davies, O.B.E.}

William Whitridge Davies, head of the Administration Division of the Road Research Laboratory of the Department of Scientific and Industrial Research, died on May 19, aged fifty-one years, after a long and painful illness borne with great fortitude. He was a nephew of the late Sir Walford Davies, Master of the King's Musick.

Mr. Davies saw service at Gallipoli as a midshipman in the Navy in the First World War, and after qualifying and practising for some ten years as a civil engineer he joined the Building Research Station. There he took a leading part in the setting 